West, B. \& Wolf, F. T. (1955). J. gen. Microbiol. 12, 396-401

\title{
The Mechanism of Action of the Fungicide, 2-Heptadecyl-2-imidazoline
}

\author{
BY B. WEST* AND F. T. WOLF \\ Department of Biology, Vanderbilt University, Nashville, Tennessee, U.S.A.
}

SUMMARY: The hypothesis that the fungicide 2-heptadecyl-2-imidazoline might owe its effectiveness to interference with the synthesis of histidine or purines was tested in experiments with Sclerotinia fructicola. The toxicity of the fungicide was significantly decreased by guanine, xanthine, or xanthosine; a number of other related compounds and histidine had no effect.

Annulment of the action of 2-heptadecyl-2-imidazoline by either xanthine or guanine was competitive. The inhibition index for 2-heptadecyl-2-imidazoline/ xanthine was 0.000581 , while that for 2-heptadecyl-2-imidazoline/guanine was 0.000832. Attempts to demonstrate the accumulation of the purine precursor 5-amino-4-imidazolecarboxamide in culture filtrates of Sclerotinia fructicola grown in the presence of the fungicide were negative.

Despite the wide use of many organic fungicides, little information is available concerning their mechanism of action (Horsfall, 1945). The present report is concerned with 2-heptadecyl-2-imidazoline(2-heptadecyl-2-glyoxalidine), the active ingredient of Crag Fruit Fungicide 341, manufactured by the Carbide and Carbon Chemicals Company, New York. This material is widely used in the control of apple scab, caused by Venturia inaequalis (Cke.) Wint., and cherry leaf spot, due to Coccomyces hiemalis Higgins (Thurston, Harry, Lewis, Groves \& Taylor, 1946; Thurston, 1950). It has previously been shown that homologues of 2-imidazoline with side chains differing in length gave dosageresponse curves which were essentially parallel, indicating that the antifungal activity was centred in the 2-imidazoline nucleus (Wellman \& McCallan, 1946). Attempts to explain fungitoxicity on the basis of surface activity (Miller, McCallan \& Weed, 1953) were unsuccessful.

Examination of the structure of 2-heptadecyl-2-imidazoline indicated similarities to certain naturally occurring compounds. The imidazole ring, present in the fungicide, is also to be found in the amino acid histidine, in allantoin, and in the purines and their derivatives. The hypothesis that the fungicide might owe its effectiveness to acting as an inhibitor of one or more of these essential metabolites was tested in a series of experiments, using Sclerotinia fructicola (Wint.) Rehm as the test organism.

\section{METHODS}

Stock cultures of an original isolate of Sclerotinia fructicola were maintained on slants of potato glucose agar at $c . \mathbf{2 6}^{\circ}$. The medium evolved after preliminary work contained (per litre) : glucose, 90 g.; L-glutamic acid, 14 g.; $\mathrm{MgSO}_{4}$. $7 \mathrm{H}_{2} \mathrm{O}$,

* First Lieutenant, USAF, Student, USAF Institute of Technology. 
0.5 g.; $\mathrm{KH}_{2} \mathrm{PO}_{4}, 1.5$ g.; $\mathrm{K}_{2} \mathrm{HPO}_{4}, 0.2$ g.; $\mathrm{FeCl}_{3}, 5 \mathrm{mg}$.; thiamine $\mathrm{HCl}, 1 \mathrm{mg}$.; $\mathrm{pH}$ adjusted to $3 \cdot 4$.

Crag Fruit Fungicide 341 consists of $34 \%(w / v)$ 2-heptadecyl-2-imidazoline acetate and $66 \%(\mathrm{w} / \mathrm{v})$ isopropanol. Dilutions were made with distilled water, and the fungicide was added to the basal medium before autoclaving.

Cultures were grown in $125 \mathrm{ml}$. Erlenmeyer flasks containing $50 \mathrm{ml}$. medium. The media were sterilized by autoclaving at $15 \mathrm{lb}$./sq.in. for $20 \mathrm{~min}$. Inoculum was prepared from cultures grown on slants of potato glucose agar for 7-9 days. Culture flasks were inoculated by means of sterile $1 \mathrm{ml}$. pipettes with a spore suspension made up in basal medium.

Cultures were incubated at $c .26^{\circ}$ under stationary conditions for 15 days. The mycelial mats were removed by filtration through filter-papers which had been previously dried to constant weight in a desiccator containing 'Drierite' (anhydrous calcium sulphate, W. A. Hammond Drierite Co., Xenia, Ohio). The filter-papers containing mycelial mats were partially.dried in an oven at $60^{\circ}$, and the drying to constant weight was completed in a desiccator containing 'Drierite'.

The concentration of purines, purine ribosides, purine ribotides, and other substances tested for possible effectiveness in annulling the action of the fungicide was routinely $1 \mathrm{mg} . / \mathrm{ml}$. These chemicals were obtained from General Biochemicals, Inc., Chagrin Falls, Ohio; Nutritional Biochemicals Corp., Cleveland, Ohio; or Dougherty Chemicals, Richmond Hill, N.Y. In experiments on the nature of the annulment, the concentrations of fungicide and other compounds were varied while keeping the fungicide/other compound ratio constant. The inhibition index (Woolley, 1952) was calculated from the concentrations of fungicide and annulling compound which give $50 \%$ inhibition of growth.

Because certain purines were shown to interfere with the function of 2-heptadecyl-2-imidazoline as a fungicide, and because 5-amino-4-imidazolecarboxamide has been shown to be a purine precursor (Stretten \& Fox, 1945; Shive, Ackermann, Gordon, Getzendaner \& Eakin, 1947), attempts were made to determine whether this compound accumulated in the filtrates of cultures whose growth was partially inhibited by the fungicide. The method used to estimate the imidazolecarboxamide, which is a general one for non-acetylable diazotizable amines, was that of Bratton \& Marshall (1939), modified by Ravel, Eakin \& Shive (1948).

\section{RESULTS}

In a preliminary experiment it was found that guanine and xanthine were very effective in annulling the action of 2-heptadecyl-2-imidazoline, while adenine, hypoxanthine, uric acid, allantoin, and L-histidine were without effect. A wider range of purines and purine derivatives, including those previously tested, 2:6-diaminopurine, caffeine, theobromine, theophylline, adenosine, guanosine, inosine, xanthosine, adenylic acid, and guanylic acid, were then tested in an experiment in which a 3.9 $\mu \mathrm{M}$ concentration of 2-heptadecyl-2-imidazoline inhibited the growth of Sclerotinia fructicola, c. $92 \%$. 
Any degree of inhibition less than this may be considered as indicative of annulment of the action of the fungicide. Using this criterion, a significant degree of annulment was found with guanine, inhibition c. $57 \%$; xanthine, inhibition $c .3 \%$; and xanthosine, inhibition c. $68 \%$; but with none of the other compounds tested. 2,6-Diaminopurine, which is readily employed as a nitrogen source by certain fungi but is inhibitory to others, was strongly inhibitory to the growth of $S$. fructicola.

Thus, of the compounds tested only guanine, xanthine or xanthosine annulled the fungicidal effect of 2-heptadecyl-2-imidazoline with certainty. An experiment was designed to examine the nature of the annulment, and to determine whether purine synthesis was affected. Purine and fungicide concentrations were varied, while the fungicide/purine ratio was kept constant. The fungicide/purine ratio chosen was equivalent to a $3 \cdot 9 \mu \mathrm{M}$ concentration of the fungicide and a $4680 \mu \mathrm{M}$ concentration of the purine. Controls were provided in which the fungicide but no purine was added to the basal medium in the concentration range studied. The results are summarized in Table 1.

Table 1. The effect of various concentrations of guanine, xanthine, and 2-heptadecyl-2-imidazoline, alone and in combination, upon the growth of Sclerotinia fructicola

\begin{tabular}{|c|c|c|c|c|c|}
\hline $\begin{array}{c}\text { Addition } \\
\text { to basal } \\
\text { medium }\end{array}$ & $\begin{array}{l}\text { Amount of } \\
\text { purine } / 50 \mathrm{ml} \text {. } \\
\text { (mg.) }\end{array}$ & $\begin{array}{c}\text { Fungicide } \\
\quad(\mu \mathrm{M})\end{array}$ & $\begin{array}{l}\text { Mat weight, } \\
\text { purine plus } \\
\text { fungicide } \\
\text { (mg.) }\end{array}$ & $\begin{array}{c}\text { Mat } \\
\text { weight, } \\
\text { fungicide } \\
\text { (mg.) }\end{array}$ & $\begin{array}{l}\text { Growth, } \\
\text { percentage } \\
\text { of control }\end{array}$ \\
\hline None & $\mathbf{0}$ & o & $749 *$ & —* & $100 \cdot 0 \dagger$ \\
\hline \multirow[t]{6}{*}{ Guanine } & 100 & $7 \cdot 811$ & 639 & 33 & $5 \cdot 2$ \\
\hline & 66.7 & $5 \cdot 207$ & 790 & 35 & $4 \cdot 4$ \\
\hline & 50 & 3.906 & 612 & 30 & $4 \cdot 9$ \\
\hline & $33 \cdot 4$ & $2 \cdot 603$ & 654 & 203 & $31 \cdot 0$ \\
\hline & 25 & $1 \cdot 953$ & 1079 & 754 & $60 \cdot 6$ \\
\hline & 20 & $1 \cdot 562$ & 843 & 738 & $87 \cdot 5$ \\
\hline \multirow[t]{6}{*}{ Xanthine } & 100 & $7 \cdot 811$ & 839 & 33 & $3 \cdot 9$ \\
\hline & $66 \cdot 7$ & $5 \cdot 207$ & 769 & 35 & $4 \cdot 6$ \\
\hline & 50 & 3.906 & 722 & 30 & $4 \cdot 2$ \\
\hline & $33 \cdot 4$ & $2 \cdot 603$ & 784 & 203 & $27 \cdot 2$ \\
\hline & 25 & 1.953 & 1208 & 754 & $62 \cdot 7$ \\
\hline & 20 & 1.562 & 938 & 738 & 78.7 \\
\hline
\end{tabular}

* All figures in these columns represent the average of duplicate determinations.

$\dagger$ Amount of growth in the absence of purine, as percentage of amount of growth in presence of purine.

Certain conclusions are evident from the data included in Table 1. In the guanine experiments, in which both the fungicide and guanine concentrations were varied by a factor of five, while the guanine/fungicide ratio was constant, roughly the same amount of growth was found in all instances. The amount of growth is therefore not proportional to either the fungicide concentration or to the guanine concentration, but is dependent on the fungicide/guanine ratio. Similar findings are evident also with xanthine. It may be concluded that annulment of the action of the fungicide by guanine or xanthine is competitive.

The data concerning guanine in Table 1 are presented graphically in Fig. 1. 
The inhibition indices characteristic of the annulment of the action of 2-heptadecyl-2-imidazoline upon the growth of Sclerotinia fructicola by guanine or xanthine were calculated as 0.000832 and 0.000581 respectively. Guanine was then considerably more effective than xanthine in annulling the action of 2-heptadecyl-2-imidazoline.

It seemed a reasonable inference from the preceding experiments, in which it was shown that certain purines annulled the action of 2-heptadecyl-2-imidazoline upon Sclerotinia fructicola, that the fungicide blocks the synthesis of

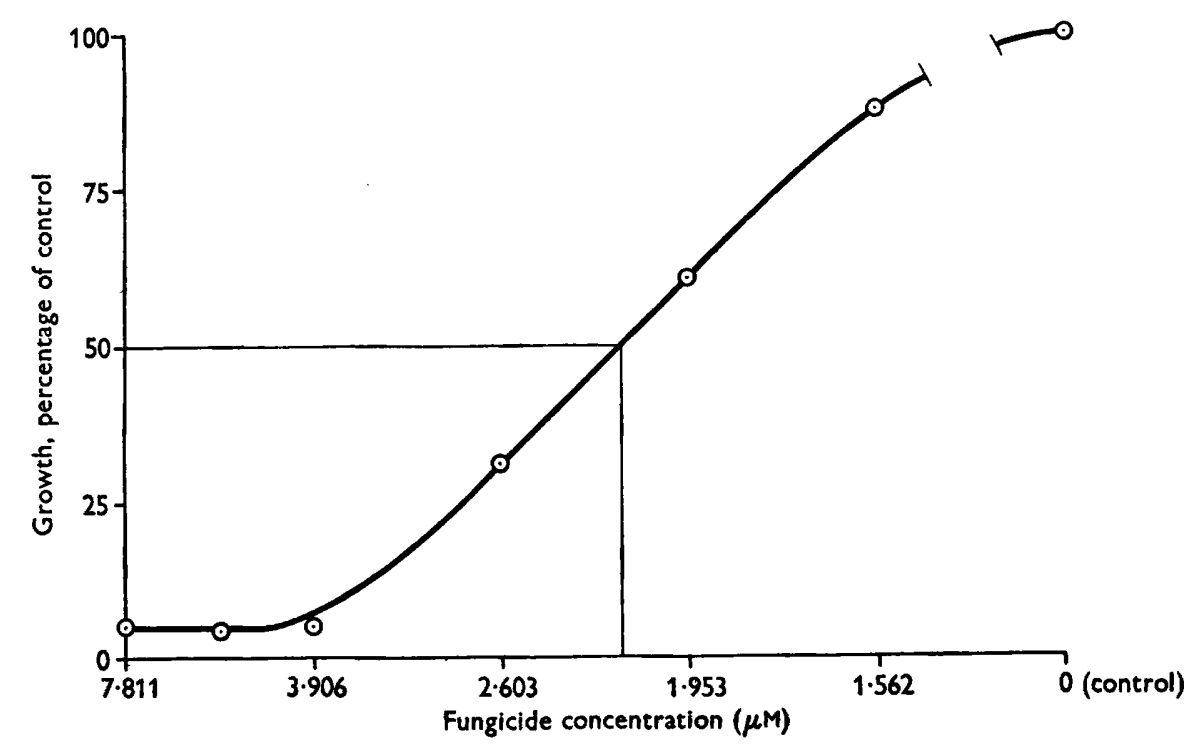

Fig. 1. Growth of Sclerotinia fructicola in various concentrations of 2-heptadecyl-2-imidazoline, expressed as a percentage of growth in controls lacking guanine, when compared with growth in a 3.9:4.680 fungicide:guanine mixture having the same fungicide concentration as the controls.

these purines, which are essential for growth. If this were so, a purine precursor might accumulate in the filtrates of cultures, the growth of which has been partially inhibited by the fungicide. One such purine precursor already known is 5-amino-4-imidazolecarboxamide (Stetten \& Fox, 1945; Shive et al. 1947). Experiments were performed in which culture filtrates of $S$. fructicola, partially inhibited by 2-heptadecyl-2-imidazoline, were examined for the presence of such a diazotizable amine by the method of Bratton \& Marshall (1939) as modified by Ravel, Eakin \& Shive (1948). Culture filtrates of $S$. fructicola grown on the basal medium alone, in the presence of $3.9 \mu \mathrm{M}-2$-heptadecyl2-imidazoline, in the presence of guanine, xanthine, or xanthosine $(4680 \mu \mathrm{M})$, and in combinations of fungicide and purines, were tested for diazotizable amines with consistently negative results; the method would have indicated c. $2 \cdot 5 \mu$ g. 5-amino-4-imidazolecarboxamide $/ \mathrm{ml}$. 


\section{DISCUSSION}

The experiments reported indicate that the fungistatic activity of 2-heptadecyl-2-imidazoline is counteracted by guanine, xanthine, or xanthosine, but not by other purines, purine derivatives, histidine, or allantoin. The compounds annulling the action of the fungicide are closely related structurally, guanine differing from xanthine only in having an amino group in the 2-position. Guanine is easily converted to xanthine in a number of organisms by a simple deamination reaction. The experiments with guanine or xanthine in combination with 2-heptadecyl-2-imidazoline indicate that the latter compound is a competitive inhibitor in the synthesis of these purines. The small inhibition indices indicate the high effectiveness of 2-heptadecyl-2-imidazoline as a purine inhibitor.

The nature of the enzyme or enzymes acted upon by 2-heptadecyl-2-imidazoline was not revealed in these experiments; they might be presumed to function in the biosynthesis of guanine and xanthine. The failure to detect a diazotizable amine does not necessarily indicate that one is not an intermediate in purine synthesis, since it is possible that it is so rapidly converted to other products as to escape detection. It also seems possible, because of the specificity shown in annulling the action of 2-heptadecyl-2-imidazoline, that xanthine and guanine might be formed in Sclerotinia fructicola by a route different from that of other purines.

Appreciation is expressed to the Carbide and Carbon Chemicals Co., New York, N.Y., for the supply of Crag Fruit Fungicide 341; to Dr W. Shive, Department of Chemistry, University of Texas, Austin, Texas, for providing 5-amino-4-imidazolecarboxamide; to Dr O. Touster, Department of Biochemistry, Vanderbilt University School of Medicine, for supervising the determinations of diazotizable amines. The material included is from the thesis of the senior author, presented to the Graduate School of Vanderbilt University in partial fulfilment of the requirements for the degree of Master of Arts.

\section{REFERENCES}

Bratton, A. C. \& Marshall, Jun., E. K. (1939). A new coupling component for sulfonamide determination. J. biol. Chem. 128, 587 .

Horsfald, J. G. (1945). Fungicides and their Action. Ann. Crypt. et Phytopath. vol. Ir. Waltham, Mass.: Chronica Botanica Co.

Miller, L. P., McCallan, S. E. A. \& Weed, R. M. (1953). Rate of uptake and toxic dose on a spore weight basis of various fungicides. Contr. Boyce Thompson Inst. $17,173$.

Ravel, J. M., Eakin, R. E. \& Shive, W. (1948). Glycine, precursor of 5(4)-amino4(5)-imidazolecarboxamide. J. biol. Chem. 172, 67.

Shive, W., Ackermann, W. W., Gordon, M., Getzendaner, M. E. \& Eakin, R. E. (1947). 5(4)-amino-4(5)-imidazolecarboxamide, a precursor of purines. J. Amer. chem. Soc. 69, 725.

Stetten, M. R. \& Fox, Jun., C. L. (1945). An amine formed by bacteria during sulfonamide bacteriostasis. J. biol. Chem. 161, 333.

Thurston, Jun., H. W. (1950). Use of glyoxalidine derivatives as fruit fungicides. Agric. Chemic. 5, 28. 
Thurston, Jun., W. W., Harry, J. B., Lewis, F. H., Groves, A. B. \& Taylor, C. F. (1946). Glyoxalidine derivatives as foliage fungicides. II. Field studies. Contr. Boyce Thompson Inst. 14, 161.

Wellman, R. H. \& McCallan, S. E. A. (1946). Glyoxalidine derivatives as foliage fungicides. I. Laboratory studies. Contr. Boyce Thompson Inst. 14, 151.

Woolney, D. W. (1952). A Study of Antimetabolites, 261 pp. New York, N.Y.: John Wiley and Sons Inc.

(Received 9 September 1954) 